\title{
Contribution of subcutaneous abdominal fat on ultrasonography to carotid atherosclerosis in patients with type 2 diabetes mellitus
}

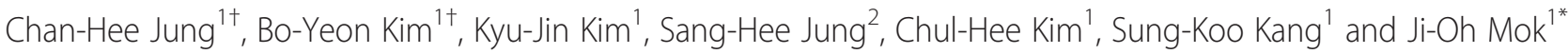

\begin{abstract}
Background: Whereas visceral abdominal adipose tissue (VAT) is associated with cardiometabolic risk, there is debate regarding the role of subcutaneous abdominal adipose tissue (SAT). The aim of this study was to investigate the relationships of subcutaneous and visceral abdominal fat with carotid atherosclerosis in patients with type 2 diabetes mellitus (T2DM).

Methods: A total of 234 patients (men 131, women 103, mean age: 53 years) with T2DM were enrolled. Carotid intima-media thickness (CIMT), abdominal subcutaneous fat thickness (SFT) and visceral fat thickness (VFT) were assessed by high-resolution B-mode ultrasonography (US).

Results: Compared to women, men had significantly higher VFT and lower SFT ( $p=0.002, p=0.04$, respectively). In partial correlation coefficient analyses between CIMT and abdominal fat thickness after adjustment for body mass index (BMI), SFT showed a negative correlation with CIMT in men $(r=-0.27, p=0.03)$. VFT was not correlated with CIMT in either men or women. In women, SFT was not correlated with CIMT ( $r=-0.01, p=0.93)$. VFT/SFT ratio was not correlated with CIMT in either men or women. In multivariate regression analyses adjusted for BMI and other CVD risk factors, SFT but not VFT was independently inversely associated with CIMT in men but not in women $(p<0.001)$. Conclusions: SFT assessed by US was inversely associated with carotid atherosclerosis in patients with T2DM, particularly men. Further research into the different roles of the two types of abdominal adipose tissue in both men and women is warranted.
\end{abstract}

Keywords: Carotid atherosclerosis, Subcutaneous abdominal fat, Subcutaneous fat thickness, Visceral fat thickness, Ultrasonography, Type 2 diabetes mellitus

\section{Background}

Obesity is associated with several types of cardiometabolic disturbances and metabolic syndrome (MS) [1]. Moreover, T2DM increases the risks of atherosclerosis and cardiovascular disease (CVD) and is known as a coronary heart disease (CHD) risk equivalent [2]. It is evident that the abdominal fat accumulation plays a central role in the pathogenesis of CVD in obese subjects [1].

Excess visceral abdominal adipose tissue (VAT) and subcutaneous abdominal adipose tissue (SAT) are key

\footnotetext{
* Correspondence: hanna@schmc.ac.kr

${ }^{\dagger}$ Equal contributors

'Division of Endocrinology and Metabolism, Department of Internal Medicine, Soonchunhyang University College of Medicine, \#170 Jomaru-ro, Wonmi-gu, Bucheon-si, Gyeonggi-do 420-767, South Korea

Full list of author information is available at the end of the article
}

contributors to abdominal obesity, but differ in their structural composition, metabolic activity, and functional significance [3]. VAT is clearly associated with increased risks of MS and CVD, whereas there has been much debate regarding the role of SAT $[4,5]$. Prospective studies have shown that the direction and strength of associations between SAT and CVD risk factors and atherosclerosis are nearly identical to those for VAT $[6,7]$. In contrast, a few studies have suggested a possible beneficial role for SAT [8]. A previous study in a sample of middle-aged men and women found that higher amounts of subcutaneous abdominal fat are associated with lower levels of subclinical atherosclerosis [9]. It remains unclear if SAT may be risk enhancing or, rather, protective for CVD. 
The standard methods of assessing abdominal fat accumulation is computed tomography (CT) and magnetic resonance imaging (MRI) [10,11]. However, several studies report that diverse indices using US are a reliable way of quantifying the visceral fat depot, and ultrasonographic VFT was strongly correlated with visceral adipose tissue by CT [12,13]. Also, reliability of the US for assessing SFT is demonstrated in several studies [14-16].

CIMT is an established marker for subclinical atherosclerosis in the general population and in individuals with diabetes $[17,18]$. Whereas recent observational studies have reported that abdominal fat accumulation on US might be associated with subclinical atherosclerosis in the general population or in the obese, there have been few studies regarding the relationship between abdominal fat assessed by US and subclinical atherosclerosis in T2DM $[13,19,20]$. Moreover, no previously published studies investigated the effects of SFT on US to detect carotid atherosclerosis in T2DM. Therefore, the aim of this study was to investigate and compare the relationships of SFT and VFT with carotid atherosclerosis and cardiovascular risk factors in patients with T2DM.

\section{Methods}

\section{Subjects}

Patients with T2DM who visited the diabetes clinic at Soonchunhyang University Bucheon Hospital from January 2012 to December 2012 were recruited. Among them, patients who had undergone thorough evaluations for carotid atherosclerosis and abdominal SFT and VFT were included in this study. Individuals with renal insufficiency, cirrhosis with ascites, known hyperthyroidism or hypothyroidism, chronic infection, malignancy, and were not available of fasting serum samples and clinical data from appropriate medical records were excluded. A total of 234 patients (mean age: 53 years) were included in this study. The alcohol consumption of the subjects was classified as 'yes or no'. The smoking status of the subjects was classified as being a non-smoker or smoker (former or current). This study was approved by the institutional review board of Soonchunhyang University Bucheon Hospital.

\section{Biomarker measurements}

All subjects underwent standard examination and testing, which included measurements of the concentrations of fasting glucose, glycated hemoglobin (HbA1c), total cholesterol (TC), low density lipoprotein cholesterol (LDL-C), high density lipoprotein cholesterol (HDL-C), triglyceride (TG), high-sensitivity C-reactive protein (hsCRP), uric acid, and homeostasis model assessment-insulin resistance (HOMA-IR). HbA1c was measured by ionexchange high-performance liquid chromography (Bio-Rad, Hercules, CA, USA).
The baPWV and ABI were measured by an automated device (VP-1000; Colin, Komaki, Japan). The PWV and $\mathrm{ABI}$, the blood pressure of both extremities, an electrocardiogram and heart sounds were measured simultaneously. The electrocardiogram electrodes were attached to both wrists and a heart sound microphone was placed on the left sterna border. Cuffs were encircled around both arms and ankles, and the cuffs were attached to both a plethymographic sensor determined the volume pulse form, and the blood pressure was measured from the oscillometric pressure sensor. PWV $(\mathrm{cm} / \mathrm{s})$ was defined as the distance between two distinct points $(\mathrm{cm})$ divided by the pulse wave transit time (s). The ABI was defined as the ratio of the systolic blood pressure measured at the ankle to the systolic blood pressure measured at the brachial artery. The insulin resistance status was evaluated by the HOMA-IR index. The HOMA-IR was calculated by the formula: [fasting insulin $(\mathrm{uIU} / \mathrm{mL}) \times$ fasting blood glucose $(\mathrm{mmol} / \mathrm{L})] / 22.5$ [21]. The HOMAIR index was available only for 159 patients who were not receiving exogenous insulin.

Diabetic nephropathy was defined using albuminuria, which was measured by radioimmunoassay (Immunotech). Albumin excretion rate (AER) $<20 \mu \mathrm{g} / \mathrm{min}$ or urine albu$\mathrm{min}<30 \mathrm{mg} / \mathrm{g}$ creatinine was categorized as normoalbuminuria, AER in the range of $20-200 \mu \mathrm{g} / \mathrm{min}$ or urine albumin $30-300 \mathrm{mg} / \mathrm{g}$ creatinine as microalbuminuria, and AER $>200 \mu \mathrm{g} / \mathrm{min}$ or urine albumin $\geq 300 \mathrm{mg} / \mathrm{g}$ creatinine as overt proteinuria. Patients were considered to have nephropathy if they show microalbuminuria or overt proteinuria.

\section{Abdominal fat and CIMT assessment by US}

Patients were weighed in light clothing, and height was measured while barefoot. Body mass index (BMI) was calculated as weight in kilograms divided by the square of height in meters. All anthropometric measurements were obtained by a skilled nurse in our diabetes clinic.

All sonographic measurements of abdominal fat thickness and carotid IMT were performed using a high resolution B-mode US (SSA-660A, Toshiba, Tokyo, Japan) by a single experienced investigator. SFT and VFT were measured in the region $1 \mathrm{~cm}$ above the umbilicus using a $12-\mathrm{MHz}$ linear-array probe and a $3.5-\mathrm{MHz}$ convexarray probe, respectively. Patients were examined during the expiratory phase of quiet respiration, and the transducer was applied on the body surface without undue pressure. SFT was defined as the maximal thickness of the fat tissue layer between the skin-fat interface and the linea alba. VFT was defined as the distance between the anterior wall of the aorta and the posterior aspect of the rectus abdominis muscle perpendicular to the aorta [20]. The intra-observer technical error of measurement for the VFT was between $1.4-2.3 \%$ and $1.1-1.7 \%$ for the SFT. 
The bilateral common carotid arteries were scanned for IMT measurement by using the SSA-660A (Toshiba) with a $12-\mathrm{MHz}$ linear transducer. The intima-media thickness was defined as the distance between the media-adventitia interface and the lumen-intima interface. Measurements of CIMT were conducted at three differential plaque free sites: the point of the greatest thickness and $1 \mathrm{~cm}$ upstream and $1 \mathrm{~cm}$ downstream of that point. The mean the three measurements of the right and left IMT was defined as the mean IMT [22].

\section{Statistical analysis}

Statistical analysis was performed using SPSS 17.0 (SPSS Inc, Chicago, IL, USA). Data are reported as mean \pm standard deviation (SD), median (interquartile range 25\%-75\%) or number of participants (percentages). Non-normally distributed variables, that is, triglyceride, hs-CRP and HOMA-IR were transformed as natural logarithms before analysis. Partial correlation analysis was performed to estimate the relationships between CIMT and VFT, SFT and other CVD risk factors adjusted for BMI. Multivariate regression analysis was performed to investigate the relationships between SAT, VAT and CIMT after adjustment for covariates including CVD risk factors. P-values $<0.05$ were considered statistically significant.

\section{Results}

Clinical characteristics of the subjects

Baseline characteristics of subjects are shown in Table 1. Of 234 patients, 131 (55.7\%) were men and 103 (43.8\%)

Table 1 Baseline characteristics of the participants

\begin{tabular}{|c|c|c|c|c|}
\hline & Total $(n=234)$ & Men $(n=131)$ & Women $(n=103)$ & P-value \\
\hline Age (Year) & $53.4 \pm 12.1$ & $52 \pm 11.9$ & $55.2 \pm 12.1$ & 0.04 \\
\hline BMI $\left(\mathrm{kg} / \mathrm{m}^{2}\right)$ & $25.2 \pm 3.8$ & $25.5 \pm 3.7$ & $25.9 \pm 3.9$ & 0.22 \\
\hline SBP $(\mathrm{mmHg})$ & $125.1 \pm 15.5$ & $126.7 \pm 16.1$ & $123.1 \pm 14.4$ & 0.07 \\
\hline $\mathrm{DBP}(\mathrm{mmHg})$ & $76.3 \pm 9.7$ & $77.3 \pm 9.6$ & $75 \pm 9.7$ & 0.07 \\
\hline HTN (\%) & $134(57.3 \%)$ & $72(55 \%)$ & $62(60 \%)$ & 0.25 \\
\hline DM duration (years) & $6.4 \pm 6.2$ & $6.1 \pm 5.9$ & $6.7 \pm 6.7$ & 0.46 \\
\hline $\mathrm{HbA} 1_{C}(\%)$ & $8.3 \pm 2.1$ & $8.4 \pm 2.2$ & $8.1 \pm 1.9$ & 0.39 \\
\hline TC (mg/dl) & $170.6 \pm 39.3$ & $167.7 \pm 39.6$ & $174.2 \pm 38.8$ & 0.22 \\
\hline LDL-C (mg/dl) & $100.8 \pm 35.5$ & $99 \pm 34.5$ & $103.1 \pm 36.7$ & 0.40 \\
\hline HDL-C (mg/dl) & $47.5 \pm 11.8$ & $45.4 \pm 11.3$ & $50.1 \pm 11.9$ & 0.003 \\
\hline Triglyceride (mg/dl) & $119(83,179)$ & $128(86,195)$ & $102(82,156)$ & 0.001 \\
\hline $\mathrm{HsCRP}(\mathrm{mg} / \mathrm{dl})$ & $0.11(0.06-0.24)$ & $0.1(0.06,0.24)$ & $0.12(0.06,0.23)$ & 0.50 \\
\hline HOMA-IR & $3.8(2.4,5.8)$ & $4.0(2.4-6.1)$ & $3.6(2.3-5.2)$ & 0.32 \\
\hline Mean ABI & $1.14 \pm 0.08$ & $1.14 \pm 0.09$ & $1.14 \pm 0.06$ & 0.89 \\
\hline Mean baPWV (cm/sec) & $1506 \pm 313$ & $1516 \pm 320$ & $1493 \pm 304$ & 0.59 \\
\hline Mean CIMT (mm) & $0.48 \pm 0.14$ & $0.48 \pm 0.15$ & $0.49 \pm 0.14$ & 0.89 \\
\hline VFT (mm) & $39 \pm 16.1$ & $41.9 \pm 15.5$ & $35.2 \pm 16.2$ & 0.002 \\
\hline SFT (mm) & $14.5 \pm 5.8$ & $13.8 \pm 6$ & $15.3 \pm 5.5$ & 0.039 \\
\hline VFT/SFT Ratio & $3.2 \pm 2.1$ & $3.5 \pm 1.7$ & $2.8 \pm 2.4$ & 0.01 \\
\hline ARB or ACEI, $\mathrm{n}(\%)$ & $94(40.2 \%)$ & $58(44.3 \%)$ & $36(35.3 \%)$ & 0.11 \\
\hline Statin, n (\%) & $133(57 \%)$ & $74(56.5 \%)$ & $59(57.8 \%)$ & 0.47 \\
\hline Antiplatelet agent, n (\%) & $105(45 \%)$ & $66(50.4 \%)$ & $39(38.2 \%)$ & 0.04 \\
\hline Thiazolidinediones, n (\%) & $21(9 \%)$ & $14(10.7 \%)$ & $7(6.8 \%)$ & 0.212 \\
\hline Smoking, n (\%) & $48(20.7 \%)$ & $43(32.8 \%)$ & $5(5 \%)$ & $<0.001$ \\
\hline Prevalence of CVD, n (\%) & $27(11.5 \%)$ & $18(13.7 \%)$ & $7(8.7 \%)$ & 0.304 \\
\hline Prevalence of DN, n (\%) & $61(26.1 \%)$ & 39 (30\%) & $22(21.4 \%)$ & 0.073 \\
\hline
\end{tabular}

Data are means \pm SD or median (interquartile range). Triglyceride, $\mathrm{HsCRP}$, Insulin, and HOMA-IR, are expressed as median (interquartile range) due to skewed distribution.

Abbreviations: BMI: body mass index; SBP: systolic blood pressure; DBP: diastolic blood pressure; HTN: hypertension; DM: diabetes mellitus; HbA1C: glycated hemoglobin; TC: total cholesterol; LDL-C: low density lipoprotein cholesterol; HDL-C: high density lipoprotein cholesterol; hsCRP: high sensitivity c-reactive protein; HOMA-IR: homeostasis model assessment-insulin resistance; $\mathrm{ABI}$ : ankle brachial index; baPWV: brachial ankle pulse wave velocity; CIMT: carotid intima media thickness; VFT: visceral fat thickness; SFT: subcutaneous fat thickness; ARB: angiotensin receptor blocker; ACEl: angiotensin converting enzyme inhibitor; CVD: cardiovascular disease; DN: diabetic nephropathy. 
were women. The mean age of all subjects was 53 years and the mean duration of diabetes was 6.4 years. One hundred and thirty four (57.3\% of total, $55 \%$ of men and $60 \%$ of women) were treated for hypertension. One hundred and thirty three (57\% of total) were treated with statin. Twenty-one (21\% of total) were treated with thiazolidinediones. The prevalence of smoking was 20.7\% (32.8\% of men and $5.0 \%$ of women). The prevalence of CVD was $11.5 \%$ ( $13.7 \%$ of men and $8.7 \%$ of women). There were no differences between men and women in mean BMI, $\mathrm{HbA1}_{\mathrm{C}}, \mathrm{TC}$, LDL-C, hs-CRP, HOMA-IR, $\mathrm{ABI}$, baPWV and CIMT. The prevalence of hypertension, prescribed medication of statin, angiotensin converting enzyme inhibitor (ACEI) or angiotensin receptor blocker (ARB), and TZD were not different between men and women. However, the men were older and tended to have lower HDL-C and higher TG. Compared to women, men had significantly higher VFT and lower SFT $(41.9 \mathrm{~mm}$ vs. $35.2 \mathrm{~mm}, 13.8 \mathrm{~mm}$ vs. $15.3 \mathrm{~mm}, \mathrm{p}=$ $0.002, \mathrm{p}=0.04$, respectively).

\section{Correlations of CIMT with VFT and SFT}

In simple correlation analysis, VFT was positively associated with BMI $(r=0.55)$, DBP $(r=0.19)$, TC $(r=0.21)$, TG $(r=0.35)$, and insulin $(r=0.23)$, and negatively associated with CIMT $(r=-0.19)$ in men. VFT was positively associated with BMI $(r=0.77)$, hs-CRP $(r=0.33)$, HbA1C $(r=0.30)$, and TG $(r=0.27)$, and negatively associated with HDL-C $(r=-0.34)$ in women. SFT showed positive correlations with BMI $(r=0.53)$ and insulin $(r=0.27)$ and negative correlations with CIMT $(\mathrm{r}=-0.33)$, baPWV $(\mathrm{r}=-0.25)$, age $(r=-0.47)$, and duration of diabetes $(r=-0.18)$ in men. SFT showed positive correlations with BMI $(r=0.54)$, hsCRP $(r=0.24)$, and TC $(r=0.20)$ and negative correlations with duration of diabetes $(r=-0.25)$ in women (data not shown). Table 2 shows partial correlation coefficients between CIMT, abdominal fat thickness and other clinical variables adjusted for BMI. After adjustment for BMI, in men, whereas VFT was not correlated with CIMT, and SFT was negatively correlated with CIMT $(\mathrm{r}=-0.15, \mathrm{p}=$ $0.18, r=-0.27, p=0.03$, respectively). In women, VFT and SFT were not correlated with CIMT $(\mathrm{r}=-0.1, \mathrm{p}=0.4$, $\mathrm{r}=-0.01, \mathrm{p}=0.93$, respectively). VFT/SFT ratio was not correlated with CIMT in either men or women (data not shown). VFT showed a negative correlation with HDL-C and SFT showed a positive correlation with HDL-C in women. However, there were no correlations between abdominal fat thickness and insulin, HOMAIR, mean baPWV and ABI after adjustment for BMI.

\section{Associations between SFT, VFT and CIMT as determined by multiple linear regression analysis}

We performed multiple regression analysis to further investigate the independent associations between SFT and
Table 2 Partial correlation coefficients of abdominal fat thickness with various variables in T2DM patients

\begin{tabular}{|c|c|c|c|c|c|c|c|c|}
\hline & \multicolumn{4}{|c|}{ VFT } & \multicolumn{4}{|c|}{ SFT } \\
\hline & \multicolumn{2}{|c|}{ Men } & \multicolumn{2}{|c|}{ Women } & \multicolumn{2}{|c|}{ Men } & \multicolumn{2}{|c|}{ Women } \\
\hline & $r$ & $p$ & $r$ & $p$ & $r$ & $p$ & $r$ & $p$ \\
\hline Age & 0.23 & 0.05 & 0.17 & 0.22 & -0.35 & $<0.01$ & -0.21 & 0.11 \\
\hline SBP & 0.13 & 0.30 & 0.10 & 0.46 & -0.03 & 0.82 & -0.15 & 0.26 \\
\hline DBP & 0.04 & 0.73 & 0.14 & 0.30 & -0.05 & 0.67 & -0.05 & 0.71 \\
\hline $\begin{array}{l}\text { DM } \\
\text { duration }\end{array}$ & 0.03 & 0.79 & -0.05 & 0.75 & -0.02 & 0.86 & -0.24 & 0.08 \\
\hline $\mathrm{HbAl}_{\mathrm{C}}$ & -0.16 & 0.20 & -0.04 & 0.76 & -0.01 & 0.94 & -0.07 & 0.60 \\
\hline TC & 0.03 & 0.80 & 0.02 & 0.85 & 0.14 & 0.27 & 0.18 & 0.18 \\
\hline LDL-C & 0.04 & $<0.01$ & 0.04 & 0.76 & 0.21 & 0.08 & 0.13 & 0.35 \\
\hline HDL-C & -0.16 & 0.20 & -0.31 & 0.02 & -0.05 & 0.70 & 0.38 & 0.01 \\
\hline TG & 0.18 & 0.15 & 0.13 & 0.35 & 0.02 & 0.89 & -0.06 & 0.67 \\
\hline $\mathrm{HsCRP}$ & 0.16 & 0.07 & -0.14 & 0.60 & -0.01 & 0.88 & -0.06 & 0.65 \\
\hline Insulin & 0.125 & 0.31 & -0.176 & 0.20 & 0.003 & 0.98 & -0.17 & 0.23 \\
\hline HOMA-IR & -0.05 & 0.64 & -0.17 & 0.21 & -0.05 & 0.71 & -0.14 & 0.30 \\
\hline CIMT & -0.15 & 0.18 & -0.10 & 0.40 & -0.27 & 0.03 & -0.01 & 0.93 \\
\hline $\mathrm{ABI}$ & -0.11 & 0.39 & -0.02 & 0.97 & -0.21 & 0.08 & -0.06 & 0.64 \\
\hline baPWV & 0.19 & 0.12 & 0.02 & 0.89 & -0.13 & 0.29 & -0.15 & 0.29 \\
\hline VFT & - & - & - & - & -0.06 & 0.65 & -0.05 & 0.71 \\
\hline SFT & -0.06 & 0.65 & -0.06 & 0.65 & - & - & - & - \\
\hline $\begin{array}{l}\text { VFT/SFT } \\
\text { ratio }\end{array}$ & 0.68 & $<0.001$ & 0.41 & $<0.01$ & -0.59 & $<0.01$ & -0.55 & $<0.01$ \\
\hline
\end{tabular}

Abbreviations: BMI: body mass index; SBP: systolic blood pressure; DBP: diastolic blood pressure; DM: diabetes mellitus; HTN: hypertension; $\mathrm{HbA1}_{\mathrm{C}}$ : glycated hemoglobin; TC: total cholesterol; LDL-C: low density lipoprotein cholesterol; HDL-C: high density lipoprotein cholesterol; hsCRP: high sensitivity c-reactive protein; HOMA-IR: homeostasis model assessment-insulin resistance; ABl: ankle brachial index; baPWV: brachial ankle pulse wave velocity; CIMT: carotid intima media thickness; VFT: visceral fat thickness; SFT: subcutaneous fat thickness.

CIMT (Table 3). To better assess the effect of gender on the association between SFT and CIMT, an interaction (gender"SFT) was evaluated first. The interaction was statistically significant $(\mathrm{p}=0.014)$ (data not shown) and then we analyzed men and women separately. As adjusting variables, we used BMI, traditional and non-traditional CVD risk factors such as SBP, LDL-C, HDL-C, age, smoking and HOMA-IR. In addition, therapeutic interventions that have been shown to influence CIMT, such as the presence of antihypertensive drugs, statin, and thiazolidinediones, were included. Multiple regression analysis using CIMT as a dependent variable showed that SFT was a significant independent contributing factor to CIMT in men but not women (beta $=-0.004, \mathrm{p}<0.001$ ). VFT was not a significant factor for CIMT in either men or women $(\mathrm{p}=0.569, \mathrm{p}=0.835$, respectively).

\section{Discussion}

In the present study, we examined the associations of VFT and SFT with carotid atherosclerosis in patients 
Table 3 Relation between abdominal fat and carotid atherosclerosis as determined by multiple linear regression analysis

\begin{tabular}{|c|c|c|c|c|c|c|}
\hline \multirow[b]{2}{*}{ Variables } & \multicolumn{3}{|c|}{$\begin{array}{c}\text { Men } \\
\left.\text { (Adjusted- } R^{2}=0.396\right)\end{array}$} & \multicolumn{3}{|c|}{ 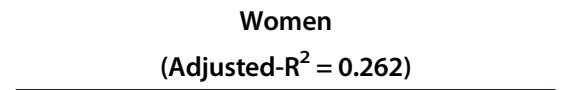 } \\
\hline & Beta & $95 \% \mathrm{Cl}$ & P-value & Beta & $95 \% \mathrm{Cl}$ & P-value \\
\hline Age (years) & 0.008 & $0.006 \sim 0.011$ & $<0.001$ & 0.007 & $0.004-0.009$ & $<0.001$ \\
\hline BMI $\left(\mathrm{kg} / \mathrm{m}^{2}\right)$ & 0.007 & $-0.05 \sim 0.048$ & 0.089 & 0.009 & $-0.004 \sim 0.021$ & 0.175 \\
\hline SBP $(\mathrm{mmHg})$ & 0.001 & $0.000 \sim 0.002$ & 0.098 & 0.001 & $-0.002 \sim 0.002$ & 0.823 \\
\hline HDL-C (mg/dl) & 0.001 & $-0.002 \sim 0.002$ & 0.748 & 0.001 & $-0.002 \sim 0.004$ & 0.424 \\
\hline LDL-C (mg/dl) & 0.001 & $0.000 \sim 0.001$ & 0.028 & 0.001 & $0.000 \sim 0.021$ & 0.213 \\
\hline $\mathrm{TG}(\mathrm{mg} / \mathrm{dl})$ & 0.001 & $0.000 \sim 0.001$ & 0.016 & -0.001 & $0.000 \sim 0.001$ & 0.766 \\
\hline HOMA-IR & 0.001 & $-0.007 \sim 0.008$ & 0.864 & -0.006 & $-0.015 \sim 0.004$ & 0.243 \\
\hline Smoking & -0.001 & $-0.050 \sim 0.048$ & 0.971 & 0.005 & $-0.147 \sim 0.158$ & 0.946 \\
\hline Treatment with statin & 0.007 & $-0.04 \sim 0.053$ & 0.780 & 0.037 & $-0.021 \sim 0.094$ & 0.206 \\
\hline $\begin{array}{l}\text { Treatment with antihypertensive } \\
\text { agents }\end{array}$ & -0.003 & $-0.051 \sim 0.046$ & 0.917 & -0.036 & $-0.103 \sim 0.031$ & 0.287 \\
\hline Treatment with TZD & -0.06 & $-0.135 \sim 0.016$ & 0.122 & 0.017 & $-0.089 \sim 0.123$ & 0.75 \\
\hline VFT (mm) & -0.001 & $-0.006 \sim 0.003$ & 0.569 & 0.001 & $-0.006 \sim 0.007$ & 0.835 \\
\hline SFT (mm) & -0.004 & $-0.005 \sim-0.002$ & $<0.001$ & -0.002 & $-0.005 \sim 0.001$ & 0.175 \\
\hline
\end{tabular}

Abbreviations: BMI: body mass index; SBP: systolic blood pressure; HDL-C: high density lipoprotein-cholesterol; LDL-C: low density lipoprotein-cholesterol TG: triglyceride; HOMA-IR: homeostasis model assessment-insulin resistance; TZD: thiazolidinedione; VFT: visceral fat thickness; SFT: subcutaneous fat thickness.

with T2DM, and demonstrated that SFT was inversely associated with CIMT after adjustments for BMI and other traditional or non-traditional CVD risk factors only in men and not in women. We found that there was a significant gender effect on the relationship between SFT and CIMT. Also, this study showed that VFT and VFT/SFT ratio were not significantly correlated with CIMT in both men and women.

Recent studies have shown that regional adiposity of the body is more closely associated with atherosclerosis than the magnitude of generalized obesity $[1,3,23]$. In particular, VAT confers risks of metabolic and CV complications $[4,24,25]$. The possibility of an active metabolic role for VAT in the etiology of MS and CVD may be explained by the fact that the VAT has higher lipolytic activity and directly releases free fatty acids into the portal circulation, and this considerably contributes to insulin resistance [26]. Khashper et al. reported that VAT thickness measured by CT scans were correlated with the presence and extent of coronary atheroma in asymptomatic subjects with DM [27]. Wang et al. showed that subjects with visceral fat areas $\geq 80 \mathrm{~cm}^{2}$ on MRI had significantly higher CIMT than those without abdominal obesity regardless of BMI in a sample of middle-aged Chinese men [28]. Kawamoto et al. found that maximal preperitoneal fat thickness assessed by US was an important risk factor for CIMT in patients aged $\geq 50$ years with BMI $\geq 23 \mathrm{kgm}^{-2}$ [20]. One study performed in a sample of 368 men with T2DM demonstrated that subjects with VFT $\geq 47.6 \mathrm{~mm}$ by US, regardless of normal waist circumference (WC), had higher CIMT compared with those with increased WC, but had less visceral fat [19]. In another study by Dahlen et al., sagittal abdominal diameter evaluated by US was more important in predicting subclinical atherosclerosis, compared with WC, in middle aged patients with type 2 diabetes [29]. However, the studies noted above did not evaluate the relationship between SAT and CIMT. In contrast with these studies, our findings indicate that VFT is not associated with CIMT in either male or female patients with T2DM. Although VFT was correlated with CIMT in men, this correlation disappeared after adjustment for BMI. Because the effects of VFT or SFT on carotid atherosclerosis vary according to categories of BMI representing general adiposity, we adjusted for BMI in our statistical analyses.

Profound endocrine and metabolic activity differences exist between visceral adipose tissue and subcutaneous adipose tissue [4]. It is unclear whether subcutaneous fat tissue may be risk enhancing or, rather, protective for CVD. Some studies have revealed that the roles of subcutaneous abdominal fat in CVD risk factors or atherosclerosis are nearly identical to those for visceral abdominal fat, whereas other studies showed that subcutaneous abdominal fat may be "less pathogenic" or protective for CVD [6-9]. Subcutaneous adipose tissue displays less lipolytic activity, releases fewer inflammatory adipocytokines and has greater adiponectin gene expression than visceral adipose tissue [4]. Subcutaneous 
adipose tissue is a preferential storage site of energy and, therefore, subcutaneous adipose tissue has been regarded as protective fat. Subcutaneous adipose tissue identified as "protective" fat depots in previous studies were mainly in non-abdominal adipose tissue regions, such as gluteal, thigh, or leg region SAT [5,30,31]. Snijder et al. suggested a protective role for peripheral subcutaneous adipose tissue, observing that increased thigh fat mass is associated with lower glucose, and lipid levels, independent of abdominal fat [5]. In study by Park et al., thigh circumference was inversely associated with CIMT in both men and women and calf circumference was negatively correlated with CIMT in women with type 2 diabetes [31]. However, one study found that subcutaneous fat accumulation, as assessed by increased hip circumference, was associated with an increased risk of T2DM and to a degree that generally similar to an increase BMI and WC. This result indicates that subcutaneous fat does not always "protect" against metabolic diseases [30]. It is possible that, if positive caloric balance results in an increase in fat weight gain, the absolute direction of adipose tissue expansion may not differ between visceral adipose tissue versus subcutaneous adipose tissue.

In addition, some reports suggest that the effects of SAT on CVD risk may depend on accompanying amounts of VAT $[30,32,33]$. Few studies have assessed potential interactions between SAT and VAT. Some authors have reported that VAT may contribute to or exacerbate the pathogenic potential of SAT, such as an increase in insulin resistance, especially in obese individuals [30,32]. On the other hand, others suggest that when there are low amounts of both VAT and SAT, the effects of lipolytic and adipokine activity by SAT on cardiometabolic risk factors are more evident. As a result, the adverse effects of SAT lessen with increasing amounts of VAT [33]. Wildman et al. examined whether VAT modifies the effects of SAT assessed by CT on CIMT in 500 European- and African-Americans. They found that when there were low amounts of VAT, more SAT was associated with a higher CIMT, whereas when there were high amounts of VAT, more SAT was associated with a lower CIMT [33]. These discrepant findings regarding the role of SAT on subclinical atherosclerosis or CVD risk factors in the literature may be due to differences in VAT amounts between participants in the previous studies. However, the mechanism underlying the potential beneficial effects of SAT in the presence of high amounts of VAT is not yet clear. Our results showed that SFT was negatively associated with CIMT in men despite adjustments for VFT and BMI. To our knowledge, few studies have focused on the measurement of SFT by US in patients with T2DM. Furthermore, no published studies have evaluated the role of SAT by US for carotid atherosclerosis in patients with T2DM.
Recently, a few studies have reported that the ratio between these two abdominal fat types (VAT:SAT) is an important tool for expressing the fat distribution in the abdomen. The ratio is strongly related to atherosclerotic risk factor and CIMT in non-obese men after adjustment of various risk factors [26]. However, the respective relationships of VFT and SFT with CIMT were not significant. In disagreement with those results, our results showed that the VFT/SFT ratio was not correlated with CIMT. Our results are in agreement with those of Yamamoto et al. [34], who reported that in 98 non-obese men, the ratio of maximum thickness of the preperitioneal fat and the minimum thickness of the subcutaneous fat, was not correlated with CIMT [35].

The standard method of measurement of abdominal fat is CT or MRI [10]. However, growing evidence reveals that US is a noninvasive and reliable method to estimate these two fat compartments. Its validity compared to CT or MRI has been tested in diverse groups including older individuals, obese adults and patients with T2DM $[11-13,25]$. To the best of our knowledge, only two studies have investigated the differential associations of VFT and SFT measured by US with subclinical atherosclerosis in T2DM, until now $[13,19]$. In agreement with other studies, we found that VFT was correlated with several CVD risk factors such as BP, TC, and TG. However, these correlations disappeared after adjustment for BMI. In the present study, VFT was not correlated with HOMA-IR representing insulin resistance.

Regional fat distribution differs by gender. Previous studies reported that there are significant gender differences in abdominal adipose tissue distributions for a given waist circumference [36,37]. Consistent with other studies, we found that men have greater VFT than women and that women have thicker SFT than men, although the mean BMIs in both men and women were similar [38]. Therefore, gender must be considered when predicting abdominal fat distributions and associated subclinical atherosclerosis. We performed multiple regression analyses for men and women after adjusting for BMI, age, and other traditional and non-traditional CVD risk factors. We found that SFT was associated with CIMT only in men, irrespective of BMI.

A large proportion of patients in our study were taking antihypertensive drugs, statin, and antidiabetic drug such as thiazolidinedione, which alter the abdominal fat thickness as well as CIMT. Several antihypertensive drugs have been shown to significantly decrease CIMT [39]. Thiazolidinediones have also been shown to decrease CIMT [40]. Moreover, the data for statins have been the most impressive in regard to their effect on CIMT [41]. Therefore, we adjusted these factors in multiple linear regression analysis. However, we could not find any significant associations between presence of therapeutic medications and CIMT. 
Previous data regarding the differential contributions of VAT and SAT to carodiometabolic risk factors and atherosclerosis have been conflicting. Previous studies varied in design, sample, and methods applied for the assessment of adipose tissue such as CT, MRI and US.

However, this study has several limitations. First, as this was a cross-sectional study, causal relationships between SFT and CIMT cannot be determined. Second, because our study sample included individuals who received carotid US examination for evaluation of diabetic complications, some characteristics of our sample may be substantially different from those of other samples. In addition, relatively young patients without other cardiovascular risk factors except diabetes are tend to not to be ordered carotid US, while elderly patients or those with $\mathrm{CV}$ risk factors are tend to be ordered US. These factors can be selection bias in this study. Third, since some of the study population had several CVD risk factors such as hypertension and dyslipidemia, we could not completely eliminate the possible effects of underlying disease or medications. Fourth, this study lacked a non-T2DM control. Therefore, the generalizability of our study may be limited. Futher prospective population-based studies are required to address this important question. Fifth, the sample size was relatively small. However, previous studies have included only about 300 subjects. A larger number of patients should be analyzed for the confirmation of our results. Sixth, we used US for the measurement of fat thickness because it was considered the best costeffective method at this time. Although CT and MRI are more accurate methods for the measurement of fat thickness, exposure to ionizing radiation of the former and the high cost of the later limit their usage.

\section{Conclusions}

We demonstrated that SFT assessed by US is associated with CIMT in male patients with T2DM, irrespective of BMI. To our knowledge, this is the first study demonstrating a negative association between SFT and CIMT in patients with T2DM. However, whether SFT assessed by US may be an important predictive factor for subclinical atherosclerosis in T2DM or not, further prospective studies with much larger sample sizes are needed.

\footnotetext{
Abbreviations

VAT: Visceral adipose tissue; SAT: Subcutaneous abdominal adipose tissue; T2DM: Type 2 diabetes mellitus; US: Ultrasonography; CIMT: Carotid intimamedia thickness; VFT: Visceral fat thickness; SFT: Subcutaneous fat thickness; MS: Metabolic syndrome; CVD: Cardiovascular disease; CHD: Coronary heart disease; CT: Computed tomography; MRI: Magnetic resonance imaging; HbA1c: Glycated hemoglobin; TC: Total cholesterol; LDL-C: Low density lipoprotein cholesterol; HDL-C: High density lipoprotein cholesterol; TG: Triglyceride; hs-CRP: High-sensitivity C-reactive protein; HOMAIR: Homeostasis model assessment-insulin resistance; baPWV: Brachial ankle pulse wave velocity; ABI: Ankle brachial index; DN: Diabetic nephropathy; BMI: Body mass index; SD: Standard deviation; SBP: Systolic blood pressure;
}

DBP: Diastolic blood pressure; ACEl: Angiotensin converting enzyme inhibitor; ARB: Angiotensin receptor blocker.

\section{Competing interests}

We declare that there are no competing interests.

\section{Authors' contributions}

$\mathrm{CHJ}, \mathrm{BYK}, \mathrm{KJK}, \mathrm{SHJ}, \mathrm{CHK}, \mathrm{SKK}$ and JOM contributed to the design, analysis and interpretation of this study. BYK and KJK contributed to the collection of clinical and laboratory data. BYK, CHJ and SHJ contributed to the writing of this manuscript. JOM revised the manuscript and contributed to the discussion. All authors read and approved the final manuscript.

\section{Authors' information}

Chan-Hee Jung and Bo-Yeon Kim are first authors.

\section{Acknowledgements}

We acknowledged the contribution of Yeon-Hee Lee for measurements of abdominal fat thickness and CIMT on US in clinical research. Also, we would like to thank Ji Sung Lee for statistical assistance. This study was supported by a grant from the Soonchunhyang University.

\section{Author details}

'Division of Endocrinology and Metabolism, Department of Internal Medicine, Soonchunhyang University College of Medicine, \#170 Jomaru-ro, Wonmi-gu, Bucheon-si, Gyeonggi-do 420-767, South Korea. ${ }^{2}$ Department of Obstetrics and Gynecology, Cha University School of Medicine, Bundang, South Korea.

Received: 26 December 2013 Accepted: 26 March 2014

Published: 28 March 2014

\section{References}

1. Larsson B, Svardsudd K, Welin L, Wilhelmsen L, Bjorntorp P, Tibblin G: Abdominal adipose tissue distribution, obesity, and risk of cardiovascular disease and death: 13-year follow-up of participants in the study of men born in 1913. Br Med J 1984, 288:1401-1404.

2. Juutilainen A, Lehto S, Ronnemaa T, Pyorala K, Laakso M: Type 2 diabetes as a "coronary heart disease equivalent". An 18-year prospective population-based study in Finnish subjects. Diabetes Care 2005, 28:2901-2907.

3. Bluher M: Adipose tissue dysfunction in obesity. Exp Clin Endocrinol Diabetes 2009, 117:241-250.

4. Wajchenberg BL: Subcutaneous and visceral adipose tissue: their relation to the metabolic syndrome. Endocrine Rev 2000, 21:697-738.

5. Snijder MB, Visser M, Dekker JM, Goodpaster BH, Harris TB, Kritchevsky SB, DeRN, Kanaya AM, Newman AB, Tylavsky FA, Seidell JC: Low subcutaneous thigh fat is a risk factor for unfavourable glucose and lipid levels, independently of high abdominal fat. The Health ABC Study. Diabetologia 2005, 48:301-308.

6. Liu J, Fox CS, Hickson DA, May WD, Hairston KG, Carr JJ, Taylor HA: Imact of abdominal visceral and subcutaneous adipose tissue on cardiometabolic risk factors: the Jackson Heart Study. J Clin Endocrinol Metab 2010, 95:5419-5426.

7. Pou KM, Massaro JM, Hoffmann U, Vasan RS, Maurovich-Horvat P, Larson MG, Keaney JF Jr, Meigs JB, Lipinska I, Kathiresan S, Murabito JM, O'Donnell CJ, Benjamin EJ, Fox CS: Visceral and subcutaneous adipose tissue volumes are cross-sectionally related to markers of inflammation and oxidative stress: the Framingham Heart Study. Circulation 2007, 11:1234-1241.

8. Silaghi A, Piercecchi-Marti MD, Grino M, Leonetti G, Alessi MC, Clement K, Dadoun F, Dutour A: Epicardial adipose tissue extent: relationship with age, body fat distribution, and coronaropathy. Obesity (Silver Spring) 2008, 16:2424-2430.

9. Narumi H, Yoshida K, Hshimoto N, Umehara I, Funabashi N, Yoshida S Komuro I: Increased subcutaneous fat accumulation has a protective role against subclinical atherosclerosis in asymptomatic subjects undergoing general health screening. Int J Cardiol 2009, 135:150-155.

10. Armellini $F$, Zamboni $M$, Robbi $R$, Todesco $T$, Rigo $L$, Bergamo-Andreis $I A$ Bosello O: Total and intra-abdominal fat measurements by ultrasound and computerized tomography. Int J Obes Relat Metab Disord 1993, $17: 209-214$ 
11. Rolfe EDL, Sleigh A, Finucane FM, Brage S, Stolk RP, Cooper C, Sharp SJ, Wareham NJ, Ong KK: Ultrasound measurements of visceral and subcutaneous abdominal thickness to predict abdominal adiposity among older men and women. Obesity 2010, 18:625-631.

12. Stolk RP, Wink O, Zelissen PM, Meijer R, van Gils AP, Grobbee DE: Validity and reproducibility of ultrasonography for the measurement of intraabdominal adipose tissue. Int J Obes Relat Metab Disord 2001, 25:1346-1351.

13. Kim SK, Kim HJ, Hur KY, Choik SH, Ahn CW, Lim SK, Kim KR, Lee HC, Huh KB, Cha BS: Visceral fat thickness measured by ultrasonography can estimate not only visceral obesity but also risks of cardiovascular and metabolic diseases. Am J Clin Nutr 2004, 79:593-599.

14. Pontiroli AE, Pizzocri P, Giacomelli M, Marchi M, Vedani P, Cucchi E, Orena C, Folli F, Pagonelli M: Ultrasound measurement of visceral and subcutaneous fat in morbidly obese patients before and after laparoscopic adjustable gastric banding: comparison with computerized tomography and with anthropometric measurements. Obes Surg 2002, 12:648-651.

15. Lee MJ, Shin DH, Kim SJ, Oh HJ, Yoo DE, Kim JK, Park JT, Han SH, Kang SW, Choi $\mathrm{KH}$, Yoo TH: Visceral fat thickness is associated with carotid atherosclerosis in peritoneal dialysis patients. Obesity (Silver Spring) 2012, 20:1301-1307

16. Karabulut A, Yaylali GF, Demirlenk S, Sevket O, Acun A: Evaluation of body fat distribution in PCOS and its association with carotid atherosclerosis and insulin resistance. Gynecol Endocrinol 2012, 28:111-114.

17. Lorenz MW, Markus HS, Bots ML, Rosvall M, Sitzer M: Prediction of clinical cardiovascular events with carotid intima-media thickness: a systematic review and metaanalysis. Circulation 2007, 115:459-67.

18. Jung CH, Baek AR, Kim KJ, Kim BY, Kim CH, Kang SK, Mok JO: Association between cardiac automonic neuropathy diabetic retinopathy and carotid atherosclerosis in patients with type 2 diabetes. Endocrinol Metab 2013, 28:1-11

19. Kim SK, Park SW, Kim SH, Cha BS, Lee HC, Cho YW: Visceral fat amount is associated with carotid atherosclerosis in type 2 diabetic men with a normal waist circumference. Int J Obes (Lond) 2009, 33:131-135.

20. Kawamoto R, Ohtsuka N, Ninomiya D, Nakamura S: Association of obesity and visceral fat distribution with intima-media thickness of carotid arteries in middle aged and older persons. Intern Med 2008, 47:143-149.

21. Mattews DR, Hosker JP, Rudenski AS, Naylor BA, Treacher DF, Turner RC: Homeostasis model assessment: insulin resistance and beta-cell function from fasting plasma glucose and insulin concentrations in man. Diabetologia 1985, 28:412-419.

22. Chambless LE, Folsom AR, Clegg LX, Sharrett AR, Shahar E, Nieto FJ, Rosamond WD, Evans G: Carotid wall thickness is predictive of incident clinical stroke: the Atherosclerosis Risk in Communities Study. Am J Epidemiol 2000, 151:478-487.

23. Divers J, Wagenknecht LE, Bowden DW, Carr JJ, Hightower RC, Ding J, Xu J, Langefeld CD, Freedman Bl: Regional adipose tissue associations with calcified atherosclerotic plaque: African American-Diabetes Heart Study. Obesity (Silver Spring) 2010, 18:2004-2009.

24. Jang EH, Kim NY, Park YM, Kim MK, Baek KH, Song KH, Lee KW, Kwon HS: Influence of visceral adiposity on cardiovascular autonomic neuropathy in patients with type 2 diabetes mellitus. Diabetes Metab J 2012, 36:285-292.

25. Sturm W, Sandhofer A, Engl J, Laimer M, Molnar C, Kaser S, Weiss H, Tilg H, Ebenbichler CF, Patsch JR: Influence of visceral obesity and liver fat on vascular structure and function in obese subjects. Obesity (Silver Spring) 2009, 17:1783-1788.

26. Bjorntorp P: Metabolic implications of body fat distribution. Diabetes Care 1991, 14:1132-1143.

27. Khashper A, Gaspar T, Azencot M, Dobrecky-Mery I, Peled N, Lewis BS, Halon DA: Visceral abdominal adipose tissue and coronary atherosclerosis in asymptomatic diabetics. Int J Cardiol 2013, 162:184-188.

28. Wang Y, Ma X, Zhou M, Zong W, Zhang L, Hao Y, Zhu J, Xiao Y, Li D, Bao Y, Jia W: Contribution of visceral fat accumulation to carotid intima-media thickness in a Chinese population. Int J Obes 2012, 36:1203-1208.

29. Dahlén EM, Bjarnegård N, Länne T, Nystrom FH, Ostgren CJ: Sagittal abdominal diameter is a more independent measure compared with waist circumference to predict arterial stiffness in subjects with type 2 diabetes- a prospective observational cohort study. Cardiovasc Diabetol 2013, 12:55.

30. Bays HE, Fox KM, Grandy S, SHIED Study Group: Anthropometric measurements and diabetes mellitus: clues to the "pathogenic" and "protective" potential of adipose tissue. Metab Syndr Relat Disord 2010, 8:307-315.

31. Park JS, Cho MH, Ahn CW, Kim KR, Huh KB: The association of insulin resistance and carotid atherosclerosis with thigh and calf circumference in patients with type 2 diabetes. Cardiovasc Diabetol 2012, 11:62.

32. Porter SA, Massaro JM, Hoffmann U, Vasan RS, O'Donnell CJ, Fox CS: Abdominal subcutaneous adipose tissue: a protective fat depot? Diabetes Care 2009, 32:1068-1075.

33. Wildman RP, Janssen I, Khan UI, Thurston R, Barinas-Mitchell E, Khoudary SRE, Everson-Rose SA, Kazlauskaite R, Matthews KA, Sutton-Tyrrell K: Subcutaneous adipose tissue in relation to subclinical atherosclerosis and cardiometabolic risk factors in midlife women. Am J Clin Nutr 2011, 93:719-726.

34. Kawamoto R, Oka Y, Tomita H, Kodama A, Ootsuka N: Association between abdominal wall fat index on ultrasonography and carotid atherosclerosis in non-obese men. J Atheroscler Thromb 2005, 12:85-91.

35. Yamamoto M, Egusa G, Hara H, Yamakido M: Association of intraabdominal fat and carotid atherosclerosis in non-obese middle-aged men with normal glucose tolerance. Int J Obes Relat Metab Disord 1997, 21:948-951.

36. Kotani K, Tokunaga K, Fujioka S, Kobatake T, Keno Y, Yoshida S, Shimomura I, Tarui S, Matsuzawa Y: Sexual dimorphism of age-related changes in whole-body fat distribution in the obese. Int J Obes Relat Metab Disord 1994, 18:207-2.

37. Schreiner PJ, Terry JG, Evans GW, Hinson WH, Crouse JR III, Heiss G: Sex-specific associations of magnetic resonance imaging-derived intraabdominal and subcutaneous fat areas with conventional anthropometric indices. The Atherosclerosis Risk in Communities Study. Am J Epidemiol 1996, 144:335-345.

38. Kuk JL, Lee SJ, Heymsfield SB, Ross R: Waist circumference and abdominal adipose tissue distribution: influence of age and sex. Am J Clin Nutr 2005, 81:1330-1334

39. Terpstra WF, May JF, Smit AJ, Graeff PA, Meyboom-de Jong B, Crijns HJ: Effects of amlodipine and lisinopril on intima-media thickness in previously untreated, elderly hypertensive patients (the ELVERA trial). J Hypertens 2004, 22:1309-1316.

40. Sidhu JS, Kaposzta Z, Markus HS, Kaski JC: Effect of rosiglitazone on common carotid intima-media thickness progression in coronary artery disease patients without diabetes mellitus. Arterioscler Thromb Vasc Biol 2004, 24:930-934.

41. Probstfield JL, Margitic SE, Byington RP, Eseland MA, Furberg CD: Results of the primary outcome measure and clinical events from the asymptomatic carotid artery progression study. Am J Cardiol 1995, 76:47-53C.

\section{doi:10.1186/1475-2840-13-67}

Cite this article as: Jung et al: Contribution of subcutaneous abdominal fat on ultrasonography to carotid atherosclerosis in patients with type 2 diabetes mellitus. Cardiovascular Diabetology 2014 13:67.

\section{Submit your next manuscript to BioMed Central and take full advantage of:}

- Convenient online submission

- Thorough peer review

- No space constraints or color figure charges

- Immediate publication on acceptance

- Inclusion in PubMed, CAS, Scopus and Google Scholar

- Research which is freely available for redistribution 